\title{
SUMMER SCHOOLS IN NUCLEAR CHEMISTRY
}

\author{
Final Progress Report
}

February 15, 1991 - February 14, 1992

\author{
Dr. Patricia A. Baisden, Project Director \\ Division of Nuclear Chemistry and Technology \\ American Chemical Society
}

January 1992

\section{PREPARED FOR THE U. S. DEPARTMENT OF ENERGY UNDER GRANT NUMBER DE-FG05-89ER75464}

\section{DISCLAIMER}

\begin{abstract}
This report was prepared as an account of work sponsored by an agency of the United States Government. Neither the United States Government nor any agency thereof, nor any of their employees, makes any warranty, express or implied, or assumes any legal liability or responsibility for the accuracy, completeness, or usefulness of any information, apparatus, product, or process disclosed, or represents that its use would not infringe privately owned rights. Reference herein to any specific commercial product, process, or service by trade name, trademark, manufacturer, or otherwise does not necessarily constitute or imply its endorsement, recommendation, or favoring by the United States Government or any agency thereof. The views and opinions of authors expressed herein do not necessarily state or reflect those of the United States Government or any agency thereof.
\end{abstract}




\section{DISCLAIMER}

Portions of this document may be illegible in electronic image products. Images are produced from the best available original document. 
PROGRESS REPORT

SUMMER SCHOOLS IN NUCLEAR CHEMISTRY

GRANT: DE-FG057-89ER75464

(February 15, 1991 - February 14, 1992)

In August of 1990, we began the process of soliciting applications. Articles advertising the Summer School appeared in the weekly journal of the American Chemical Society, (ACS), Chemical and Engineering News, the Journal of Chemical Education, and the ACS Student Affiliates Newsletter, the Hilter. In addition, color posters (attachment) were sent out to the chairmen of all US colleges and universities which offer at least a BS degree in chemistry and to the student advisors of ACS Student Affiliate Chapters. In all, over 2100 posters were mailed. In addition, color posters were also distributed to interested parties at national ACS meetings. For your information, a copy of the student application packet for the Summer School is enclosed.

We received about 89 requests for applications and after prescreening the applications, 58 were sent to the selection committee. Members of the selection committee included: Dr. John Wild (Lawrence Livermore National Lab, Chairman), Dr. Joanna Fowler (Brookhaven National Lab), Prof. Joseph Peterson (University of Tennessee), and Dr. David Pruett (Oak Ridge National Laboratory). The selection committee returned a list in rank order from 1 to 50 . During the second week of March, the students were notified of their selection. Of the top 24 students selected, 6 declined. The students not accepting our offer declined in favor of accepting undergraduate research positions at various universities or salaried summer jobs. The assignment of a student to one or the other of the Summer Schools was made on the basis of balancing the numbers of students from large or small schools, the number of sophomores and juniors, the number of males and females at each site.

One month after the requisite 24 fellowships were awarded and the alternate candidates were informed that the positions were filled, one student who was assigned to the Brookhaven site (Michael Buehler, Genesco State University, NY) informed us that he would have to withdraw. Due to the lateness of his withdrawal, we were unable, after several weeks of effort, to fill his slot. Therefore, only 11 students participated in the Summer School at Brookhaven.

The class of '91 at San Jose State University consisted of 8 males and 4 females. Of the twelve students, 8 had just completed their sophomore year of college and the remaining 4, their junior year. The class of '91 at Brookhaven National Lab consisted of 7 males and 4 females with the number of sophomores and juniors being 6 and 5 respectively. 
The colleges or universities represented by the 1991 Summer Schools classes are listed below by site:

\section{Brookhaven National Lab}

Carnegie-Mellon University, Pittsburgh, PA

DePaul University, Chicago, IL

Immaculata College, Immaculata, PA

Lawrence Technological University, Southfield, MI

Monmouth College, Monmouth, IL

Northwestern University, Evanston, IL

Pomona College, Claremont, CA

Rochester Institute of Technology, Rochester, NY

University of Pennsylvania, Philadelphia, PA

University of Southern Maine, Portland, ME

University of Wisconsin/Madison, Madison, WI

\section{$\underline{\text { San Jose State University }}$}

Berea College, Berea, KY

Centre College, Danville, KY

Georgetown College, Georgetown, KY

Georgia Institute of Technology, Atlanta, GA

Lock Haven College, Lock Haven, PA

Marquette University, Milwaukee, WI

Middlebury College, Middlebury, VT

Moorhead State University, Fargo, ND

Northwestern University, Evanston, IL

Texarkana College, Texarkana, TX

University of Denver, Denver, CO

University of Wisconsin-River Falls, River Falls, WI

All the transportation details were taken care of and airline tickets and final instructions to the participants were sent certified mail during the third week of May. The students arrived for the Summer School on Sunday, June 23, and were met at either the Long Island MacArthur (BNL) or the San Jose (SJSU) airports by a greeting committee composed of several local members of the ACS Division of Nuclear Chemistry and Technology. After providing ground transportation to their places of residence for the six-week period, a meeting was held to introduce the students to their instructors and to give them their textbooks and course material.

Since the course contents, special lectures, and field trips differed somewhat at each location, they will be treated separately in this progress report. 
The Summer School in Nuclear Chemistry

San Jose State University

(Prepared by Professor Alan C. Ling)

The 1991 Summer School in Nuclear Chemistry began on Sunday June 23, 1991, and ended on Friday August 2, 1991. Twelve students attended the program at San Jose State University, the list of 12 attendees is attached to this report. The program commenced with a Sunday afternoon orientation meeting, extending from approximately 6:00 p.m. through to 9:00 p.m. The curriculum was similar to that taught during the summer of 1990, and included lectures and laboratory sessions covering (but no limited to) the following:

History of nuclear science.

Introductory nuclear science and radiochemistry.

Radiochemistry instrumentation.

Gas fluid counters and spectrometers, liquid scintillation spectrometers, solid state ionization detectors such as $\mathrm{Ge}, \mathrm{GeLi}, \mathrm{SiLi}$, and $\mathrm{Si}$ surface barrier detectors, health physics monitoring equipment, and associated instrumentation.

Health physics, radiological safety, federal and state regulatory concerns.

Nuclear chemistry and interactions of radiation with matter.

Applications of nuclear science to various other disciplines.

Nuclear power, waste control, and environmentai concerns.

The summer program included special shortcourses on neutron activation analysis, fundamental particles, and nuclear medicine; three field trips to (LBL, LLNL, \& MBARI); and various guest teachers and guest speakers. This latter category included the following persons:

Steven Yates - University of Kentucky (Spin Isomers in Nucleii).

Greg Choppin - Florida State University (Nuclear Reactors and Nuclear Waste Control).

Tom Cahill - University of California at Davis (Environmental Concerns of Nuclear Reactors, and Environmental Control of Radio-Nuclides).

Glenn Seaborg - University of California at Berkeley (Transuranic Elements).

Walt Loveland - Oregon State University (Nuclear Reactors in University Research).

Joe Peterson - University of Tennessee (Inorganic Chemistry of TransActinides).

John Bigelow - Oak Ridge National Laboratory (Cf-252 Sources).

Darleane Hoffman - University of California at Berkeley (Nuclear Fission). Michael Welch - Washington University at St. Louis (Nuclear Medicine). William Eckelmann - NIH at Gaithersburg, Maryland (Nuclear Medicine). Scott Landvetter - Smith, Kline, and Beckmann Corporation (Nuclear Medicine). 
Craig Stone - San Jose State University (Nuclear Data-Bases).

Brad Stone - San Jose State University (Fundamental Particles).

Peter Englert - San Jose State University (Activation Analysis).

Norman McElroy - San Jose State University (Health Physics and Regulatory Agencies).

Allen Tucker - San Jose State University (Accelerator Dating Techniques for C-14).

Visitors also included several students from past years, including Howard Hall (\#1 student from 1984), Alan Veeck (\#1 student from 1990), and nearly half-a-dozen other students from 1984 to 1990.

As well as attending lectures from (nominally) 8:30 a.m. to noon, and laboratory sessions from 1:00 p.m. to 5:30 p.m., there were several weekend events, major term papers, oral seminar presentation by each student, four two hour examination, and considerable one-on-one tutoring. Five textbooks were purchased for the students. San Jose State University issued six semester units of academic credit to each student, corresponding to one unit of health physics and radiological safety, two units of lecture material in nuclear chemistry, and three units of laboratory work.

My general impressions are that this group of students was average with respect to academic abilities, but well above average with respect to esprit-de-corps. In fact, this was perhaps the most "cohesive" group of students since Year One in 1984. This latter effect was encouraged strongly by an increased emphasis on social interactions, in that students went to dinner with each of the speakers, and in addition, there were several weekend social events and study sessions initiated by the SJSU teaching staff. Indications are that most of these students will go on to graduate school in nuclear science or nuclear medicine, which is the primary mission of this program.

The number one student selected from the 1991 Summer School was David Shuman (from Middlebury College). As is usual, I also named a number two student, Erica Larsen (from Marquette University in Milwaukee). David Shuman was brought to the Fall National Meeting of the American Chemical Society, where he addressed the Division of Nuclear Chemistry and Technology, and attended the presentations and papers given at that meeting.

Below is a list of the students that attended the Summer School in Nuclear Chemistry at San Jose State University:

Howe, Jay D.

Texarkana College, Texarkana, TX 75501

Kriner, John D. Jr.

Lock Haven University, Lock Haven, PA 17745 
Larson, Erica J.

Marquette University, Milwaukee, WI 53233

Martin, Michelle

University of Wisconsin-River Falls, River Falls, WI 54022

Pfohl, Jeffrey S.

Centre College, Danville, KY 40422

Shuman, David S.

Middlebury College, Middlebury, VT 05753

Smith, Lee Ann

Berea College, Berea, KY 40404

Smith, William E.

Moorhead State University, Fargo, ND 56560

Szewczyk, Jason W.

Northwestern University, Evanston, IL 60201

Ta, Thong Quang

University of Denver, Denver, CO 80210

Tolbert, Lara M.

Georgia Institute of Technology, Atlanta, GA 80332

Vincent, Jacob W.

Georgetown College, Georgetown, KY 40324 


\section{The Summer School in Nuclear Chemistry \\ Brookhaven National Laboratory \\ (Prepared by Dr. Seymour Katcoff)}

Eleven undergraduate students majoring in chemistry attended the six week lecture and laboratory program in nuclear and radiochemistry from June 24 to August 2. The regular class work was supplemented by special guest lectures, a nuclear medicine symposium, visits to nuclear and medical research facilities, and a field trip to a nuclear power plant.

The lecture topics included: rate of decay and properties of radioactive nuclei; nuclear stability and structure; nuclear reactions and fission; interaction of radiation with matter; and applications of radiochemistry in medicine and industry. The main lecturers were Dr. Daeg Brenner of Clark University, Dr. John Alexander of the State University of New York at Stony brook, and Dr. Garman Harbottle (BNL). Since there are many expert scientists at Brookhaven who specialize in areas closely related to the topis of the lecture course, we invited a few of them as guest lecturers. These included L. Mausner (radiation biology), G. VanTuyle (nuclear power), and E. M. Franz (nuclear waste management.). Dr. Glen Gordon from the University of Maryland gave a seminar talk on environmental radiochemistry. The nuclear medicine symposium featured talks on the role of radiochemists in the development of radionuclides and radiopharmaceuticals for SPECT and PET (see below). In the last week of the program there were lectures on special topics:

R. Hahn on discovery of heavy elements; G. Friedlander on cluster impact fusion; R. Davis on solar neutrinos; and P. Haustein on radioactive beams. One morning per week was devoted to discussions and problem solving. Two examinations were given and each student also wrote a 1500 word term paper on which he/she presented a 15 minute oral report.

The laboratory experiments included: preparation of radioactive samples; use of gas proportional counters, $\mathrm{NaI}, \mathrm{Ge}$, and surface barrier detectors; activation analysis; isotope dilution applications; $x$-ray fluorescence analysis; and liquid scintillation counting. The students wrote laboratory reports and were tested by a final examination. The course was supervised by Dr. Yung Yee Chu of BNL with assistance of James Keenan (Albany Medical College) and Edward Baum (University of Kentucky).

This year the field trip was to the Indian Point Nuclear Power Plant at Buchanan, New York, operated by the N. Y. Power Authority. Our host was Dr. John Kelly who is in charge of radiological health and chemistry. He arranged a very comprehensive tour including excellent talks and demonstrations which showed the important role played by chemists in nuclear power plants.

In addition to the formal school program, we had several receptions, dinners, and parties. Thus, the students had the opportunity to meet informally with a considerable number of nuclear chemists and researchers in nuclear medicine. 
Three alumni of the 1990 Summer Schools also attended these events because they were at Brookhaven for ten weeks in a summer student research program.

The student survey and questionnaire showed that they were generally very satisfied with the summer school and would recommend it to other students, although they thought the workload excessive. All the students expect to attend graduate school or medical school, and ten of these said they would continue their study of nuclear chemistry, radiochemistry, or nuclear medicine.

The list of students who attended the Summer School is given below. Mr. Thomas Kayani was selected as the "outstanding student" to attend the national meeting of the American Chemical Society in New York the last week of August, all expenses paid.

Broderick, Peter S.

University of Wisconsin, Madison, WI 53706

Brylski, Robert D.

University of Wisconsin, Oshkosh, WI 54901

Davin, Brian P.

Lawrence Tech. University, Southfield, MI 48075

Downer, Joanna B.

Carnegie Mellon University, Pittsburgh, PA 15213

Fang, Eric $Y$.

Pomona College, Claremont, CA 91711

Feil, Janine F.

DePaul University, Chicago, IL 60614

Kayani, Thomas J.

University of Pennsylvania, Philadelphia, PA 19104

Kim, Joseph

Northwestern University, Evanston, IL 60201

Moyer, Martin P.

Rochester Institute of Technology, Rochester, NY 14623

Muhlena, Martha M.

Monmouth College, Monmouth, IL 61462

Smith, Eliot A.

University of Southern Maine, Portland, ME 04101 


\section{General Comments}

From the questionnaires and surveys completed by the students at both sites (see enclosures for copies of the questionnaires and student survey), all of the students indicated that they expected to continue their education at the graduate level. The results also indicated that most intended to consider highly graduate studies in some aspect nuclear chemistry, radiochemistry, or nuclear medicine. The students at both SJSU and BNL were highly motivated and performed extremely well over the intensive, six-week period. They appeared to greatly appreciate the opportunity to get a broad overview of nuclear and radiochemistry and a chance to carry out some hands-on experiments. They also had some good suggestions at each site for ways to improve the program which we hope to incorporate next year.

Due to the mismatch in timing associated with submitting the new proposal and having to begin soliciting applications, we have already printed and mailed the color poster announcing the 1992 Summer Schools in Nuclear Chemistry. We have already sent requests to advertise the 1992 Summer School to the usual publications and we expect that the announcements will appear in the October time frame. The proposed dates for 1992 Summer Schools are June 22 to July 31. (See attached new color poster for 1992). Please note that Professor Alan C. Ling from San Jose State University will assume the responsibilities of Project Director for the Summer Schools in Nuclear Chemistry beginning in 1992.

From the class of '90, eight students were assisted in obtaining employment during the summer of 1991:

Lawrence Livermore National Laboratory (1)

Brookhaven National Laboratory (3)

Los Alamos National Laboratory (2)

Argonne National Lab (1)

Lawrence Berkeley Laboratory (1) 


\section{Undergraduate Fellowship Program}

\section{Summer Schools in Nuclear Chemistry}

Western site:

San Jose State University

San Jose, California
Eastern site:

Brookhaven National Laboratory

Upton, Long Island, New York

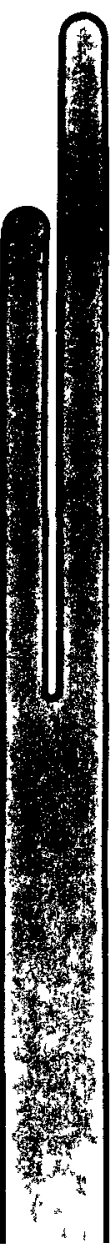

June 24-August 2, 1991

The Division of Nuclear Chemistry and Technology of the American Chemical Society (ACS) is sponsoring two intensive six-week Summer Schools in Nuclear Chemistry for undergraduates.

Award - Fellowships include transportation to and from the Summer School site, room and board, books, and student fees.

Qualifications - Candidates must be undergraduate chemistry majors who will be entering their junior or senior year in the fall of 1991. They must have completed at least two years of chemistry, one year of physics, and one year of calculus prior to the Summer Schools.

Selection - The Summer Schools will be limited to 24 students, 12 at each site. Candidates will be selected by a joint committee composed of members of the Committee on Nuclear and Radiochemistry of the National Academy of Sciences/National Research Council and the ACS Division of Nuclear Chemistry and Technology. Students will be assigned to each site based on criteria developed by the selection committee.

Course Description - The course will consist of both lecture and laboratory 


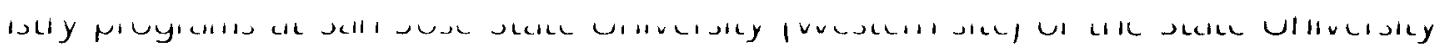
of New York at Stony Brook (Eastern site). In addition to the formal instruction. the course will include a Guest Lecture Series and tours of nearby national laboratories, universities, and nuclear industries with facilities for nuclear chemistry and radiochemistry basic and applied research. Through the Guest Lecture Series, the participants will meet and speak with prominent scientists in the nuclear research community. A workshop on nuclear medicine will also be included in the course.

Employment Opportunities - Graduates of the Summer Schools will be assisted in finding employment the following summer in national laboratories, universities, or industry.

Funding - Primary funding for the Summer Schools is being provided by the Department of Energy-Office of Energy Research (Division of University and Industry Programs and Division of Chemical Sciences), with additional support fro' the Lawrence Livermore National Laboratory.

To Apply - For an application packet, write to:

Summer Schools in Nuclear Chemistry

ATTN: Dr. Patricia A. Baisden L-234

Lawrence Livermore National Laboratory

P.O. Box 808

Livermore, CA 94551

\section{Completed applications must be received no later than January 30, 1991.}




\section{SUMMER SCHOOL IN NUCLEAR CHEMISTRY Undergraduate Fellowship Program}

I request confidential evaluation for the purpose of determining suitability for acceptance to the Summer School in Nuclear Chemistry Undergraduate Fellowship Program to which I am applying. I will not ask access to this evaluation.

Signature of Student:

TO APPLICANT:

Please complete the boxed section below before submitting this form to your referee.

LAST FIRST MIDDLE

APPLICANTS NAME

Please describe contacts with the person completing this reference

\section{TO REFEREE:}

The student named above is applying for admission to an intensive six week Summer School in Nuclear Chemistry for undergraduates sponsored by the Nuclear Chemistry and Technology Division of the American Chemical Society. If successful the applicant will receive a fellowship which includes transportation, room and board, books and student fees. Undergraduate chemistry majors who complete the sophomore or junior year prior to next summer are eligible to apply.

Please complete this personal reference form and return it by January 30 to the address on the reverse side. If you do not know the student well enough to give him or her a recommendation, check here $\square$.

1. Overall scholarly ability,

$\begin{array}{ll}\text { 口-- Outstanding } & \text { (Comparable to the best student in current class, highest 5\%) } \\ \text {-- Very good } & \text { (Next highest 10\%) } \\ \text {-- Good } & \text { (Ability easily identifiable, in upper 25\%) } \\ \text {-- Average } & \text { (Upper 50\%) } \\ \text {-- Below Average } & \end{array}$

2. Some gifted students compile mediocre scholastic records. In your opinion, is the applicant's record, as you know it, an accurate index of his or her ability ? $\square$ - Yes, $\square-$ No, $\square$ - Don't know. If your answer is "No," please comment below. 


\section{SUMMER SCHOOL IN NUCLEAR CHEMISTRY Undergraduate Fellowship Program}

I request confidential evaluation for the purpose of determining suitability for acceptance to the Summer School in Nuclear Chemistry Undergraduate Fellowship Program to which I am applying. I will not ask access to this evaluation.

Signature of Student:

TO APPLICANT:

Please complete the boxed section below before submitting this form to your referee.

\begin{tabular}{|l|l|}
\hline APPLICANTS NAME & MAST \\
\hline Please describe contacts with the person completing this reference \\
\end{tabular}

\section{TO REFEREE:}

The student named above is applying for admission to an intensive six week Summer School in Nuclear Chemistry for undergraduates sponsored by the Nuclear Chemistry and Technology Division of the American Chemical Society. If successful the applicant will receive a fellowship which includes transportation, room and board, books and student fees. Undergraduate chemistry majors who complete the sophomore or junior year prior to next summer are eligible to apply.

Please complete this personal reference form and return it by January 30 to the address on the reverse side. If you do not know the student well enough to give him or her a recommendation, check here

1. Overall scholarly ability,

-- Outstanding
-- Very good
-- Good
-- Average
-- Below Average

(Comparable to the best student in current class, highest 5\%) (Next highest 10\%) (Ability easily identifiable, in upper $25 \%$ )

(Upper 50\%)

2. Some gifted students compile mediocre scholastic records. In your opinion, is the applicant's record, as you know it, an accurate index of his or her ability ? - - Yes, $\square$ - No, $\square$ - Don't know. If your answer is "No," please comment below. 


\section{Course Questionnaire}

In order to provide information to help improve the summer school course which you have just completed and to learn of your evaluation of various aspects of the program, we ask you to answer the following questions. Circle the most appropriate answer in each case, where 5 is highest (good, very satisfactory, etc.) and 1 is lowest (poor, not satisfactory, etc.)

1. How helpful were the following to you:

Highest Average Lowest
a) the textbook (FKMM)?
b) the textbook (WWL)?
$\begin{array}{lllll}5 & 4 & 3 & 2 & 1\end{array}$
c) other textbook (K)?
d) handouts?

$\begin{array}{lllll}5 & 4 & 3 & 2 & 1\end{array}$

$\begin{array}{lllll}5 & 4 & 3 & 2 & 1\end{array}$

$\begin{array}{lllll}5 & 4 & 3 & 2 & 1\end{array}$

2. How well did the lectures complement the textbook?

$\begin{array}{lllll}5 & 4 & 3 & 2 & 1\end{array}$

3. Were the lectures well organized?

$\begin{array}{lllll}5 & 4 & 3 & 2 & 1\end{array}$

4. How well did the lectures make concepts understandable?

$\begin{array}{lllll}5 & 4 & 3 & 2 & 1\end{array}$

$\begin{array}{llllllll}\text { 5. Did the lecturers welcome questions in class? } & 5 & 4 & 3 & 2 & 1\end{array}$

$\begin{array}{lllllllll}\text { 6. Were the lecturers available outside of class } & 5 & 4 & 3 & 2 & 1\end{array}$ to answer questions?

7. How do you rate the lecture part of this course compared to your advanced chemistry courses?

8. Did the guest lecturers add to the value of the $\quad \begin{array}{lllllll}5 & 4 & 3 & 2 & 1\end{array}$ course?

9. Did you have sufficient opportunity to talk $\quad \begin{array}{lllllll}5 & 4 & 3 & 2 & 1\end{array}$ with the guest lecturers?

10. How valuable were the field trips?

$\begin{array}{lllll}5 & 4 & 3 & 2 & 1\end{array}$

11. Was the laboratory worth all the time required?

$\begin{array}{lllll}5 & 4 & 3 & 2 & 1\end{array}$

12. How well did the laboratory develop your skills?

$\begin{array}{lllll}5 & 4 & 3 & 2 & 1\end{array}$

$\begin{array}{lllll}5 & 4 & 3 & 2 & 1\end{array}$

13. How well did the laboratory help make the $\begin{array}{llllllll}5 & 4 & 3 & 2 & 1\end{array}$ lecture concepts more understandable? 
14. How helpful were the laboratory assistants? $\quad \begin{array}{lllllll}5 & 4 & 3 & 2 & 1\end{array}$

$\begin{array}{lllllllll}\text { 15. Were the laboratory assistants sufficiently } & & 5 & 4 & 3 & 2 & 1\end{array}$ available for questions outside the lab?

16. How do you rate the laboratory compared to $\begin{array}{llllllll}5 & 4 & 3 & 2 & 1\end{array}$ your advanced chemistry laboratories?

17. How useful was it to have physical chemistry $\begin{array}{lllllll}5 & 4 & 3 & 2 & 1\end{array}$ before taking this course?

18. To what extent has this course increased your $\quad \begin{array}{llllll}5 & 4 & 3 & 2 & 1\end{array}$ interest in nuclear/radiochemistry as a career?

19. How satisfactory were the housing facilities? $\begin{array}{lllllll}5 & 4 & 3 & 2 & 1\end{array}$

$\begin{array}{llllllll}\text { 20. How satisfactory were the meals? } & 5 & 4 & 3 & 2 & 1\end{array}$

21. Which topic in the lectures did you find
a) most interesting?
b) least interesting?

22. Which laboratory experiment was
a) most interesting?
b) least interesting?

23. Which Guest Lecture was the most interesting?

24. What other topics would you have been interested in hearing as a part of the Guest Lecture Series? 
25. Did you find the $\varepsilon_{\mathrm{r}}$ - ial lectures/workshops interesti

a) Which special lecture was most interesting?

b) Which special lecture was least interesting?

c) Did you find it confusing to have several different lecturers speak on different topics to the class?

Explain

26. How did you find out about the Summer School?

a) the color poster

b) article in Chemical and Engineering News

c) article in pHilter (Student Affiliates Newsletter)

d) other:

27. Would you suggest any changes in the way the travel arrangements were handled?

28. What were the greatest strengths of the Summer School program? 
29. What were the gicaiest weaknesses of the Summer school program?

30. Please add your suggestions on how to improve this program.

31. Additional comments: 
Name:

Address where you can most commonly be reached:

Phone Number:

Are you interested in summer employment next summer in the field of Nuclear or Radiochemistry? Yes No

If you answered yes to the above question:

Based on your experience at the Summer School or any other information you have received elsewhere, in what area or areas would you like to gain additional experience through summer employment? (e.g., environmental radiochemistry, accelerator work, nuclear medicine, radioanalytical chemistry, actinide chemistry, study of nuclear reactions, etc.)

Would you prefer employment at a national laboratory or a university?

(Circle one, or both if you have no preference.)

Do you have a geographical preference for employment? Yes No If yes, where?

After completion of your undergraduate degree, do you plan to attend graduate school? Yes No

Date you expect to receive your undergraduate degree:

Do you plan to attend medical school after graduation? Yes No Based on your experience at the Summer School:

a. Are you interested in pursuing graduate studies in the field of Nuclear or Radiochemistry? Yes No

b. Are you interested in pursuing graduate studies in the field of Nuclear Medicine? Yes No

c. After completing the Summer School, would you recommend this program to other students? Yes No 
Dr. Alan Campbell Ling

Dean, College of Science

San Jose State University

San Jose, CA 95192 